\title{
Association between preoperative serum total cholesterol level and biochemical recurrence in prostate cancer patients who underwent radical prostatectomy
}

\author{
YOSHIO OHNO, MAKOTO OHORI, JUN NAKASHIMA, HIDENORI OKUBO, \\ NAOYA SATAKE, TAKESHI HASHIMOTO and MASAAKI TACHIBANA \\ Department of Urology, Tokyo Medical University, Tokyo 1600023, Japan
}

Received September 4, 2015; Accepted March 7, 2016

DOI: $10.3892 /$ mco.2016.831

\begin{abstract}
The aim of this study was to investigate the association between serum total cholesterol (TC) level and biochemical recurrence $(\mathrm{BCR})$ following radical prostatectomy (RP). The study included 562 patients with T1-3N0M0 prostate cancer, who underwent RP at our institution between 2002 and 2010. No patients received neoadjuvant and/or adjuvant therapy. The associations between preoperative TC level, clinicopathological factors and BCR were assessed using univariate and multivariate analyses. During follow-up (mean, 54.0 months), 168 patients $(168 / 562,29.9 \%)$ experienced BCR, with a 5-year BCR-free rate of $67.2 \%$. Of the clinicopathological characteristics investigated, statin use and lymphovascular invasion (LVI) status were associated with lower TC level $(\mathrm{P}=0.003$ and $\mathrm{P}=0.014$, respectively). In the univariate analysis, a higher serum prostate-specific antigen (PSA) level at diagnosis, extracapsular extension, positive surgical margin, seminal vesicle invasion, LVI, perineural invasion, higher Gleason score (GS $\geq 8$ ) based on the RP specimen, increased body mass index, and low preoperative TC level, were significantly associated with BCR. In the multivariate analysis, the TC level was an independent predictor of BCR (hazard ratio $=0.925$ per $10 \mathrm{mg} / \mathrm{dl}$; 95\% confidence interval: 0.879-0.973; $\mathrm{P}=0.003$ ), as was the serum PSA level, extracapsular extension, positive surgical margin and the GS. Low preoperative serum TC levels were associated with an increased risk of BCR among prostate cancer patients who underwent RP. Our findings suggest that the preoperative serum TC level may provide important clinical information that may prove to be useful in patient counseling.
\end{abstract}

Correspondence to: Dr Yoshio Ohno, Department of Urology, Tokyo Medical University, 6-7-1 Nishishinjuku, Shinjuku-ku, Tokyo 1600023, Japan

E-mail: yoshio-o@tokyo-med.ac.jp

Key words: prostate cancer, prostatectomy, total cholesterol, recurrence, prostate-specific antigen

\section{Introduction}

Following introduction of the prostate-specific antigen (PSA) screening test, the majority of prostate cancer patients are diagnosed in the early stages of the disease and undergo definitive local treatment, such as radical prostatectomy (RP) and radiotherapy. However, a subset of patients experience biochemical recurrence (BCR) or succumb to prostate cancer $(1,2)$. Thus, prevention of recurrence and progression to lethal prostate cancer represents a major public health challenge.

The established risk factors for prostate cancer are age, race and family history, which are all non-modifiable (1). To date, several researchers have investigated the association between modifiable lifestyle factors, such as obesity, smoking and a high-fat diet, and the risk and prognosis of prostate cancer $(1,3)$. The identification of modifiable factors that affect the clinical course of prostate cancer may be useful for preventing recurrence and progression after definitive local treatment. Recent studies have demonstrated a decreased risk of high-grade prostate cancer in men with lower circulating total cholesterol (TC) levels (4-6). In addition, several studies reported that statin, a cholesterol-lowering drug, may protect against high-stage or high-grade prostate cancer (7). Furthermore, it has been demonstrated that statins decrease the risk of BCR or prostate cancer-specific mortality $(8,9)$. However, to date, only a limited number of studies have investigated the association between pretreatment serum TC level and the prognosis of prostate cancer, particularly in the PSA era. The aim of this study was to investigate the clinical implications of preoperative serum TC level in Japanese prostate cancer patients who underwent RP.

\section{Patients and methods}

Patients. This retrospective study was conducted according to the Ethical Guidelines for Clinical Studies of the Ministry of Health, Labor and Welfare of Japan, and was approved by the Ethics Committee of our institution (no. 1621). Clinical data from 719 Japanese patients who underwent RP and pelvic lymph node dissection for clinical T1-3NOM0 prostate cancer at our institution from 2000 to 2010 were collected by reviewing the patients' medical charts. Patients who received neoadjuvant 
hormonal therapy $(n=112)$ or high-intensity focused ultrasonography $(n=1)$ and patients with unavailable serum TC level data $(n=44)$ were excluded from the study. Finally, a total of 562 patients were included in our study. These patients were treated by open retropubic $(n=316)$ or robot-assisted $(n=246) R P$, and only lymph node sampling was performed. Clinical stages were assigned according to the 2002 TNM staging system (10), and pathology outcomes, such as pathological stage, status of surgical margins, lymphovascular invasion (LVI), perineural invasion (PNI) and the Gleason score (GS) of the RP specimens, were obtained from the official pathology reports. Peripheral blood samples were primarily obtained from all the patients at the time of hospitalization. Data on statin use was extracted from the patients' records at the time of RP. Body mass index (BMI) was calculated as weight $(\mathrm{kg})$ divided by the square of the height $\left(\mathrm{m}^{2}\right)$ and expressed as $\mathrm{kg} / \mathrm{m}^{2}$.

Data analyses. The data were expressed as mean \pm standard deviation (SD). The primary outcome measure in this study was $\mathrm{BCR}$. The time of BCR was defined as the earliest date that the postoperative serum PSA levels increased to $\geq 0.2 \mathrm{ng} / \mathrm{ml}$, and BCR was confirmed by a second PSA examination result that was equal to or higher than the initially recorded PSA levels. The day of surgery was reported as the PSA recurrence day if postoperative serum PSA levels did not decrease to $\leq 0.1 \mathrm{ng} / \mathrm{ml}$. Factors analyzed included age at RP, preoperative serum PSA levels, BMI, preoperative serum TC level, statin use, and all relevant pathological factors [GS, extracapsular extension (ECE), seminal vesicle invasion (SVI), surgical margin status, LVI, PNI and lymph node metastasis] of the RP specimen. Age at RP, preoperative serum PSA levels, BMI and preoperative TC level were included as continuous variables. BMI was also analyzed as a categorical variable in the Cox regression analyses. Patients were classified using the World Health Organization criteria as follows: BMI $<25 \mathrm{~kg} / \mathrm{m}^{2}$ (normal weight), BMI $25-30 \mathrm{~kg} / \mathrm{m}^{2}$ (overweight) and BMI $\geq 30 \mathrm{~kg} / \mathrm{m}^{2}$ (obesity) (11). The variables of the different groups were compared using the Pearson's Chi-square test, the Mann-Whitney U test, or analysis of variance. Univariate and multivariate Cox regression analyses were performed to assess the association between BCR and the clinicopathological variables. Multivariate Cox regression analyses were performed using a forward stepwise variable selection procedure, and survival curves were constructed using the Kaplan-Meier method with log-rank tests. The patients were divided into two groups by the cut-off identified by the root node in a recursive partitioning analysis according to the previous report by de Martino et al (12). All P-values were two-tailed, and P-values $<0.05$ were considered to indicate statistically significant differences. All statistical analyses were performed using Stata software, version 11 (StataCorp, College Station, TX, USA) and JMP software, version 9 (SAS Institute, Cary, NC, USA).

\section{Results}

Serum TC level and clinicopathological factors. The patients' characteristics are summarized in Table I. The mean \pm SD serum TC level of all patients was $209 \pm 32.1 \mathrm{mg} / \mathrm{dl}$ (median, $209 \mathrm{mg} / \mathrm{dl}$; interquartile range, 190-230 mg/dl). The serum TC level was found to be significantly correlated with
Table I. Patient characteristics $(\mathrm{n}=562)$.

\begin{tabular}{lc}
\hline Characteristics & Values $^{\mathrm{a}}$ \\
\hline Age, years & $65.9 \pm 6.4$ \\
PSA, ng/ml & $10.6 \pm 10.1$ \\
Body mass index, kg/m² & $23.7 \pm 2.9$ \\
$<25$ & $377(67.1)$ \\
$25-30$ & $170(30.2)$ \\
$\geq 30$ & $15(2.7)$ \\
Total serum cholesterol, mg/dl & $209 \pm 32.1$ \\
Statin use & \\
No & $493(87.7)$ \\
Yes & $69(12.3)$ \\
Clinical stage & \\
T1c & $417(71.2)$ \\
T2 & $136(27.2)$ \\
T3 & $9(1.6)$
\end{tabular}

Pathological factors

RP Gleason score

$\leq 6$

$100(17.8)$

7

$338(60.1)$

$124(22.1)$

$\geq 8$

$381(67.8)$

$(-)$

$(-)$

$7(1.2)$

$(+)$

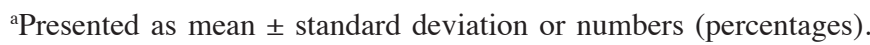
$\mathrm{RP}$, radical prostatectomy.

age (Spearman's $\mathrm{r}=-0.101, \mathrm{P}=0.016)$, but not with PSA level $(\mathrm{P}=0.737)$ or $\mathrm{BMI}(\mathrm{P}=0.274)$ (data not shown). In addition, low TC level was found to be significantly associated with statin use and presence of LVI ( $\mathrm{P}=0.003$ and $\mathrm{P}=0.014$, respectively; Table II).

Serum TC level and prognosis. During follow-up (mean, 54.0 months), 168 patients $(168 / 562,29.9 \%)$ experienced 
Table II. Association between serum TC level and clinicopathological factors.

\begin{tabular}{|c|c|c|c|}
\hline \multirow[b]{2}{*}{ Factors } & \multicolumn{2}{|c|}{ Serum TC level } & \multirow[b]{2}{*}{ P-value } \\
\hline & Mean & SD & \\
\hline Statin use & & & 0.003 \\
\hline No & 211 & 31.7 & \\
\hline Yes & 199 & 33.0 & \\
\hline Clinical T stage & & & 0.292 \\
\hline $\mathrm{T} 1 \mathrm{c}$ & 209 & 32.6 & \\
\hline $\mathrm{T} 2 \mathrm{a}$ & 217 & 32.1 & \\
\hline $\mathrm{T} 2 \mathrm{~b}$ & 211 & 28.2 & \\
\hline $\mathrm{T} 2 \mathrm{c}$ & 204 & 8.3 & \\
\hline $\mathrm{T} 3$ & 213 & 10.7 & \\
\hline Gleason score & & & 0.280 \\
\hline$\leq 7$ & 211 & 32.0 & \\
\hline$\geq 8$ & 207 & 32.2 & \\
\hline Extracapsular extension & & & 0.867 \\
\hline$(-)$ & 210 & 30.4 & \\
\hline$(+)$ & 210 & 35.5 & \\
\hline Seminal vesicle invasion & & & 0.229 \\
\hline$(-)$ & 210 & 32.2 & \\
\hline$(+)$ & 204 & 30.5 & \\
\hline Surgical margin & & & 0.232 \\
\hline$(-)$ & 208 & 32.0 & \\
\hline$(+)$ & 212 & 32.2 & \\
\hline Lymphovascular invasion & & & 0.014 \\
\hline$(-)$ & 211 & 31.9 & \\
\hline$(+)$ & 204 & 32.1 & \\
\hline Perineural invasion & & & 0.663 \\
\hline$(-)$ & 209 & 32.1 & \\
\hline$(+)$ & 210 & 32.1 & \\
\hline Lymph node metastases & & & 0.834 \\
\hline$(-)$ & 210 & 32.2 & \\
\hline$(+)$ & 212 & 22.5 & \\
\hline
\end{tabular}

SD, standard deviation; TC, total cholesterol.

BCR, with a 5-year BCR-free rate of $67.2 \%$. In the univariate analysis, a higher serum PSA level at diagnosis, advanced clinical tumor stage, ECE, positive surgical margin, SVI, LVI, PNI, higher GS (GS $\geq 8$ ) based on the RP specimen, increased BMI, and a lower preoperative serum TC level, were significantly associated with BCR (Table III). BCR-free survival curves according to the TC level are presented in Fig. 1. The cut-off TC level was defined by recursive partitioning analysis. The 5-year BCR-free rate in patients with high TC level (TC $\geq 220 \mathrm{mg} / \mathrm{dl}$ ) was higher compared with that in patients with low TC levels (TC $<220 \mathrm{mg} / \mathrm{dl}$ ) (72.8 vs. $64.0 \%$, respectively; $\mathrm{P}=0.014$ ).

In the multivariate analysis, the serum TC level was an independent predictor of BCR [hazard ratio $(\mathrm{HR})=0.925$ per $10 \mathrm{mg} / \mathrm{dl}$; 95\% confidence interval (CI): 0.879-0.973; $\mathrm{P}=0.003$ ),

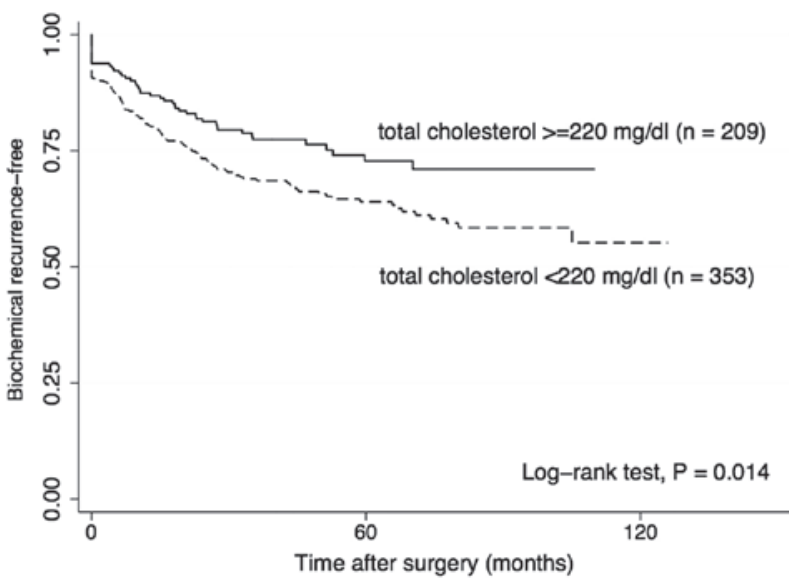

Figure 1. Biochemical recurrence-free survival rate according to preoperative serum total cholesterol level.

as was the serum PSA level, ECE, positive surgical margin and GS (Table III).

In subpopulation analyses by statin use or surgical margin status, univariate analyses demonstrated that lower preoperative serum TC level was significantly associated with BCR in the statin non-user group (HR=0.941 per $10 \mathrm{mg} / \mathrm{dl}$; 95\% CI: $0.983-0.991 ; \mathrm{P}=0.021)$ and in the negative surgical margin group (HR=0.883 per $10 \mathrm{mg} / \mathrm{dl}$; 95\% CI: 0.799-0.975; $\mathrm{P}=0.014)$.

\section{Discussion}

In this study, we demonstrated that low preoperative TC levels were significantly associated with an increased risk of BCR following RP. Previous epidemiological studies demonstrated that lower serum TC level was associated with lower risk of high-grade prostate cancer and advanced disease (4-6). It was also reported that hypercholesterolemia accelerates the growth of prostatic tumors in vivo (13). Therefore, we hypothesized that an elevated preoperative serum TC level may be associated with increased risk of BCR following RP. Contrary to our expectations, there was no significant association between preoperative serum TC level and GS and clinical stage in the present study. A Cox proportional hazard model demonstrated a dose-dependent inverse association between preoperative TC level and the risk of BCR.

To date, only a limited number of studies have described the association between serum TC level and prostate cancer prognosis. Eichholzer et al reported that low plasma TC level $(<199 \mathrm{mg} / \mathrm{dl})$ was significantly associated with an increased risk of prostate cancer mortality in individuals aged $>60$ years (14). Batty et al reported that elevated blood TC level was associated with death from prostate cancer (15). These results are inconsistent. Although it has been reported that a high TC level accelerates proliferation of prostate cancer cells, the serum TC level decreases by effect of cancer metabolism as the disease progresses (16). Thus, it may be important to consider the time interval between serum TC measurement and prostate cancer diagnosis, and the extent of the disease when investigating the association between serum TC level and prostate cancer prognosis. Solomon et al suggested that a relatively low TC 
Table III. Results of univariate and multivariate analyses.

\begin{tabular}{|c|c|c|c|c|c|}
\hline \multirow[b]{2}{*}{ Variables } & \multicolumn{2}{|c|}{ Univariate } & \multicolumn{3}{|c|}{ Multivariate } \\
\hline & HR & P-value & HR & $95 \% \mathrm{CI}$ & P-value \\
\hline \multicolumn{6}{|c|}{ Age at diagnosis, years } \\
\hline Continuous & 1.022 & 0.087 & & & 0.896 \\
\hline \multicolumn{6}{|l|}{$\mathrm{PSA}, \mathrm{ng} / \mathrm{ml}$} \\
\hline Continuous & 1.034 & $<0.001$ & 1.018 & $1.007-1.029$ & 0.002 \\
\hline \multicolumn{6}{|l|}{ Statin use } \\
\hline No vs. yes & 1.211 & 0.442 & & & 0.120 \\
\hline \multicolumn{6}{|c|}{ Clinical T stage } \\
\hline 1 & 1 & & & & \\
\hline 2 & 1.593 & 0.006 & & & 0.522 \\
\hline 3 & 10.681 & $<0.001$ & & & 0.021 \\
\hline \multicolumn{6}{|l|}{ Gleason score } \\
\hline$\leq 7$ vs. $\geq 8$ & 2.816 & $<0.001$ & 1.596 & $1.107-2.302$ & 0.012 \\
\hline \multicolumn{6}{|c|}{ Extracapsular extension } \\
\hline (-) vs. (+) & 3.910 & $<0.001$ & 1.687 & $1.136-2.503$ & 0.009 \\
\hline \multicolumn{6}{|c|}{ Seminal vesicle invasion } \\
\hline$(-)$ vs. (+) & 4.160 & $<0.001$ & & & 0.192 \\
\hline \multicolumn{6}{|c|}{ Surgical margin } \\
\hline$(-)$ vs. $(+)$ & 4.191 & $<0.001$ & 2.564 & $1.701-3.864$ & $<0.001$ \\
\hline \multicolumn{6}{|c|}{ Lymphovascular invasion } \\
\hline (-) vs. (+) & 2.279 & $<0.001$ & & & 0.184 \\
\hline \multicolumn{6}{|c|}{ Perineural invasion } \\
\hline$(-)$ vs. $(+)$ & 1.913 & $<0.001$ & & & 0.799 \\
\hline \multicolumn{6}{|c|}{ Lymph node metastases } \\
\hline$(-)$ vs. $(+)$ & 4.144 & 0.002 & & & 0.184 \\
\hline \multicolumn{6}{|c|}{ Body mass index, $\mathrm{kg} / \mathrm{m}^{2}$} \\
\hline Continuous & 1.064 & 0.018 & & & 0.240 \\
\hline \multicolumn{6}{|c|}{ Body mass index, $\mathrm{kg} / \mathrm{m}^{2}$} \\
\hline$<25$ & 1 & & - & - & - \\
\hline $25-30$ & 1.202 & 0.266 & & & \\
\hline$\geq 30$ & 2.716 & 0.007 & & & \\
\hline \multicolumn{6}{|c|}{ Serum total cholesterol $(10 \mathrm{mg} / \mathrm{dl})$} \\
\hline Continuous & 0.995 & 0.030 & 0.925 & $0.879-0.97$ & 0.003 \\
\hline
\end{tabular}

HR, hazard ratio; CI, confidence interval; PSA, prostate-specific antigen.

level within 1 year of a prostate cancer diagnosis raises the risk of prostate cancer-related death; a relatively low TC level may indicate more advanced disease. On the other hand, a relatively low TC level $>6$ years prior to prostate cancer diagnosis reduces the risk of prostate cancer-related death; this may be associated with lower risk of high-grade cancer or aggressive disease (16). Although serum TC level in the present study was measured within 3 months after prostate cancer diagnosis, serum TC level in previous epidemiological studies by Platz et al and Mondull et al, which demonstrated that a lower serum TC level was associated with lower risk of high-grade prostate cancer and advanced disease, was measured at least 2 years prior to prostate cancer diagnosis (4-6). Thus, there may have been a significant difference in the clinical implications of the serum TC level in these studies.

The association between a relatively low serum TC level and $\mathrm{BCR}$ remains to be elucidated. The present study included only clinically localized disease. Thus, it was unlikely that serum TC levels were affected by prostate cancer cells. One potential explanation for the observed association between serum TC level and BCR is an association between serum TC and immune system function. It has been reported that men with hypocholesterolemia had significantly fewer circulating lymphocytes, fewer total T cells, and fewer CD8 ${ }^{+}$ cells compared with th ose with hypercholesterolemia (17). Thus, patients with relatively high TC levels may have a 
better antitumor immune status compared with patients with relatively low TC levels.

Although this study highlights the important clinical implications of preoperative serum TC level in prostate cancer patients who underwent RP, it has some limitations. First, this is a retrospective analysis of data collected from a single institution; thus, the number of cases was relatively small. Second, there may be differences in patient characteristics between studies on BCR and prostate cancer in Western countries and those in Asian countries. In Western studies, over half the study population is overweight or obese (BMI $\geq 25 \mathrm{~kg} / \mathrm{m}^{2}$ ) (18-20), whereas $<50 \%$ of the study populations in Asian studies have a BMI of $\geq 25 \mathrm{~kg} / \mathrm{m}^{2}(21,22)$. However, serum TC levels appear to be similar in Asian and Western studies $(4,5,14,23)$. Third, we only analyzed the association of the TC level with BCR, since our routine preoperative laboratory examination did not include assessment of LDL and HDL cholesterol levels. We may need to investigate the association between LDL and HDL cholesterol levels and BCR in the future. Despite these limitations, however, this is the first study to demonstrate an inverse association between preoperative serum TC level and BCR following RP. Our findings suggest that the preoperative serum TC level may provide important clinical information that may prove be useful in patient counseling. However, further large cohort studies, including different countries and regions, are warranted to validate the clinical value of preoperative serum TC level in prostate cancer patients.

In conclusion, low preoperative serum TC levels were significantly associated with an increased risk of BCR among prostate cancer patients who underwent RP. However, our findings require validation by future studies.

\section{Acknowledgements}

The present study was partially supported by the MEXT-Supported Program for the Strategic Foundation at Private Universities, 2013-2017.

\section{References}

1. Heidenreich A, Bellmunt J, Bolla M, Joniau S, Mason M Matveev V, Mottet N, Schmid HP, van der Kwast T, Wiegel T, et al: EAU guidelines on prostate cancer. Part 1: Screening, diagnosis, and treatment of clinically localised disease. Eur Urol 59: 61-71, 2011.

2. Mottet N, Bellmunt J, Bolla M, Joniau S, Mason M, Matveev V, Schmid HP, van der Kwast $T$, Wiegel $T$, Zattoni $F$ and Heidenreich A: EAU guidelines on prostate cancer. Part II: Treatment of advanced, relapsing, and castration-resistant prostate cancer. Eur Urol 59: 572-583, 2011.

3. Wilson KM, Giovannucci EL and Mucci LA: Lifestyle and dietary factors in the prevention of lethal prostate cancer. Asian J Androl 14: 365-374, 2012.

4. Platz EA, Clinton SK and Giovannucci E: Association between plasma cholesterol and prostate cancer in the PSA era. Int J Cancer 123: 1693-1698, 2008.

5. Platz EA, Till C, Goodman PJ, Parnes HL, Figg WD, Albanes D, Neuhouser ML, Klein EA, Thompson IM Jr and Kristal AR: Men with low serum cholesterol have a lower risk of high-grade prostate cancer in the placebo arm of the prostate cancer prevention trial. Cancer Epidemiol Biomarkers Prev 18: 2807-2813, 2009.
6. Mondul AM, Clipp SL, Helzlsouer KJ and Platz EA: Association between plasma total cholesterol concentration and incident prostate cancer in the CLUE II cohort. Cancer Causes Control 21: 61-68, 2010.

7. Platz EA, Leitzmann MF, Visvanathan K, Rimm EB, Stampfer MJ, Willett WC and Giovannucci E: Statin drugs and risk of advanced prostate cancer. J Natl Cancer Inst 98: $1819-1825,2006$

8. Allott EH, Howard LE, Cooperberg MR, Kane CJ, Aronson WJ, Terris MK, Amling CL and Freedland SJ: Postoperative statin use and risk of biochemical recurrence following radical prostatectomy: Results from the Shared Equal Access Regional Cancer Hospital (SEARCH) database. BJU Int 114: 661-666, 2014.

9. Yu O, Eberg M, Benayoun S, Aprikian A, Batist G, Suissa S and Azoulay L: Use of statins and the risk of death in patients with prostate cancer. J Clin Oncol 32: 5-11, 2014.

10. Sobin LH and Wittekind CH (eds.): UICC. TNM Classification of Malignant Tumours. 6th edition. Wiley, New York, 2002.

11. World Health Organization: Obesity: Preventing and Managing the Global Epidemic. WHO Technical Report Series no 894. WHO, Geneva, 2000.

12. de Martino M, Leitner CV, Seemann C, Hofbauer SL, Lucca I, Haitel A, Shariat SF and Klatte T: Preoperative serum cholesterol is an independent prognostic factor for patients with renal cell carcinoma (RCC). BJU Int 115: 397-404, 2015.

13. Zhuang L, Kim J, Adam RM, Solomon KR and Freeman MR: Cholesterol targeting alters lipid raft composition and cell survival in prostate cancer cells and xenografts. J Clin Invest 115: 959-968, 2005.

14. Eichholzer M, Stähelin HB, Gutzwiller F, Lüdin E and Bernasconi F: Association of low plasma cholesterol with mortality for cancer at various sites in men: 17-y follow-up of the prospective Basel study. Am J Clin Nutr 71: 569-572, 2000.

15. Batty GD, Kivimäki M, Clarke R, Davey Smith G and Shipley MJ: Modifiable risk factors for prostate cancer mortality in London: Forty years of follow-up in the Whitehall study. Cancer Causes Control 22: 311-318, 2011.

16. Solomon KR and Freeman MR: The complex interplay between cholesterol and prostate malignancy. Urol Clin North Am 38: 243-259, 2011.

17. Muldoon MF, Marsland A, Flory JD, Rabin BS, Whiteside TL and Manuck SB: Immune system differences in men with hypoor hypercholesterolemia. Clin Immunol Immunopathol 84: 145-149, 1997.

18. Amling CL, Kane CJ, Riffenburgh RH, Ward JF, Roberts JL, Lance RS, Friedrichs PA and Moul JW: Relationship between obesity and race in predicting adverse pathologic variables in patients undergoing radical prostatectomy. Urology 58: 723-728, 2001.

19. Siddiqui SA, Inman BA, Sengupta S, Slezak JM, Bergstralf EJ, Leibovich BC, Zincke $\mathrm{H}$ and Blute ML: Obesity and survival after radical prostatectomy: A 10-year prospective cohort study. Cancer 107: 521-529, 2006.

20. Loeb S, Yu X, Nadler RB, Roehl KA, Han M, Hawkins SA and Catalona WJ: Does body mass index affect preoperative prostate specific antigen velocity or pathological outcomes after radical prostatectomy? J Urol 177: 102-106; discussion 106, 2007.

21. Narita S, Mitsuzuka K, Yoneyama T, Tsuchiya N, Koie T, Kakoi N, Kawamura S, Kaiho Y, Oyama C, Tochigi T, et al: Impact of body mass index on clinicopathological outcome and biochemical recurrence after radical prostatectomy. Prostate Cancer Prostatic Dis 16: 271-276, 2013.

22. Lee SE, Lee WK, Jeong MS, Abdullajanov M, Kim DS, Park HZ, Jeong SJ, Yoon CY, Byun SS, Choe G, et al: Is body mass index associated with pathological outcomes after radical prostatectomy in Korean men? BJU Int 107: 1250-1255, 2011.

23. Kitahara CM, Berrington de González A, Freedman ND, Huxley R, Mok Y, Jee SH and Samet JM: Total cholesterol and cancer risk in a large prospective study in Korea. J Clin Oncol 29: 1592-1598, 2011 